Изварина Н.Ю., доцент кафедры «Экономическая безопасность, учет и право» ФГБОУ ВО «Донской государственный технический университет», Ростов-на-Дону, Россия; nata_don@mail.ru

Тепегенджиян А.А., студент 4 курса кафедры «Экономическая безопасность, учет и право» ДГТУ, Ростов-на-Дону, Россия;angelina.tepenzi@gmail.com

Филев Д.В., студент 4 курса кафедры «Экономическая безопасность, учет и право» ДГТУ, Ростов-на-Дону, Россия;filiev94.25.99.z@gmail.com

\title{
РИСК-ОРИЕНТИРОВАННЫЙ АУДИТ
}

Аннотация. В статье рассмотрены особенности построения системы внутреннего аудита в целях экономической безопасности предприятия. Особый акцент сделан на риск-ориентированном подходе к внутреннему аудиту. Предложена модель риск-ориентированного внутреннего аудита, представлены его основные преимущества. Встатье предложены актуальные направления использования внутреннего аудита.

Ключевые слова: аудит, контроль, внутренний контроль, риск в аудите, внутренний аудит.

Izvarina N. Y., associate Professor of the Department of Economic security, accounting and law, don state technical University, Rostov-on-don, Russia; nata_don@mail.ru

A. A. Tepegenjyan, 4th year student of the Department of Economic security, accounting and law, DSTU, Rostov-on-don, Russia; angelina.tepenzi@gmail.com

D. V. Filev, 3rd year student of the Department of Economic security, accounting and law, DSTU, Rostov-on-don, Russia; filiev94.25.99.z@gmail.com

\section{RISK-BASED AUDIT}

Annotation. The article discusses the features of building an internal audit system for the economic security of an enterprise. Special emphasis is placed on a risk-based approach to internal audit. A flowchart of the risk-based approach is proposed in which its main advantages are written. Ways to solve emerging problems in the field of internal audit are also suggested.

Keywords: audit, control, internal control, risk in audit, internal audit. 
В настоящее время существует объективная потребность в разработке методики риск-ориентированного аудита для формирования практики его использования для управленческих решений в системе корпоративного управления большинсвта крупных компаний. Наличие внутреннего контроля в системе корпоративного управления, если оно правильно организовано и осуществляется в соответствии с утвержденными миссией и стратегией развития, позволяет внутренним аудиторам оперативно выявлять признаки риска и сообщать о них вышестоящему руководству компании.

Качественная информация должна соответствовать признакам достоверности, целостности и своевременности. Однако лица, принимающие решения, часто действуют в условиях существующей неопределенности и риска, которые вызваны непредвиденной и неполной бухгалтерской и аналитической информацией, на основе которой формируются проекты решений. Поэтому задача внутреннего аудита - минимизировать (нейтрализовать) негативные риски за счет их своевременного выявления и дальнейшей оценки. Актуальным направлением работы службы внутреннего аудита выступает смещение ракурса их внимания от соответствия законодательным нормам и положениям к внутренним локальным стандартам, позволяющим выстроить работу службы внутреннего аудита таким образом, чтобы его деятельность позволяла нейтрализовать риски потери прибыли от основных бизнес-процессов.

В результате деятельность службы внутреннего аудита сосредоточена на риск-ориентированном подходе, который направлен на своевременную оценку эффективности деятельности организации, выявление негативных рисков, а также на разработку проектов рекомендаций по минимизации рисков. Целью данной статьи является обоснование и определение роли аудита, основанного на оценке рисков.

Подход к процессу внутреннего аудита, основанный на оценке рисков, должен основываться на эффективных методах и процедурах, позволяющих своевременно выявлять риски и факторы неэффективного использования 
активов и собственных средств организация. В зависимости от того, насколько хорошо составлен план работы соответствующей структуры в компании, процедуры, используемые в процессе проверки, и качество рекомендаций, которые внутренний аудитор может дать по управлению рисками или по устранению последствий рисковых ситуаций, будут определяться на основе их идентификации, оценки и всестороннего анализа.

Деятельность компании подвержена влиянию многих факторов риска. Некоторые факторы риска могут сами спровоцировать реализацию определенного риска, другие - только в сочетании с другими. Факторы риска влияют на эффективность бизнес-процессов. Анализируя факторы риска в отношении процессов, в которых они возникают, внутренний аудитор может использовать свои профессиональные качества. В этом суть рискориентированного подхода к внутреннему аудиту: проанализировать, что мешает компании достичь своей цели, и найти лучший способ нивелировать негативное воздействие на эту цель рисковых факторов.

В рамках риск-ориентированного подхода можно выделить два базовых метода, а именно:

- упрощенный метод;

- расширенный метод.

Эффективность использования любого из этих методов повышается с ростом квалификации и опыта внутреннего аудитора. Например, продвинутые аудиторы могут не участвовать в детальной оценке процессов с использованием факторов риска, но они немедленно оперируют отдельными рисками и цепочками рисков различной сложности, имея лишь фрагментарную информацию об объекте аудита, даже если они не посещали его ранее.

При применении упрощенного метода необходимо учитывать особенности, представленные данными рисунка 1. 
Количество факторов риска ничем не ограниченно

Доступны списки из многих факторов, поэтому несмотря на то, что внутренний аудитор может быть ограничен ресурсами, увеличение их количества для анализа, улучшает качество оценки

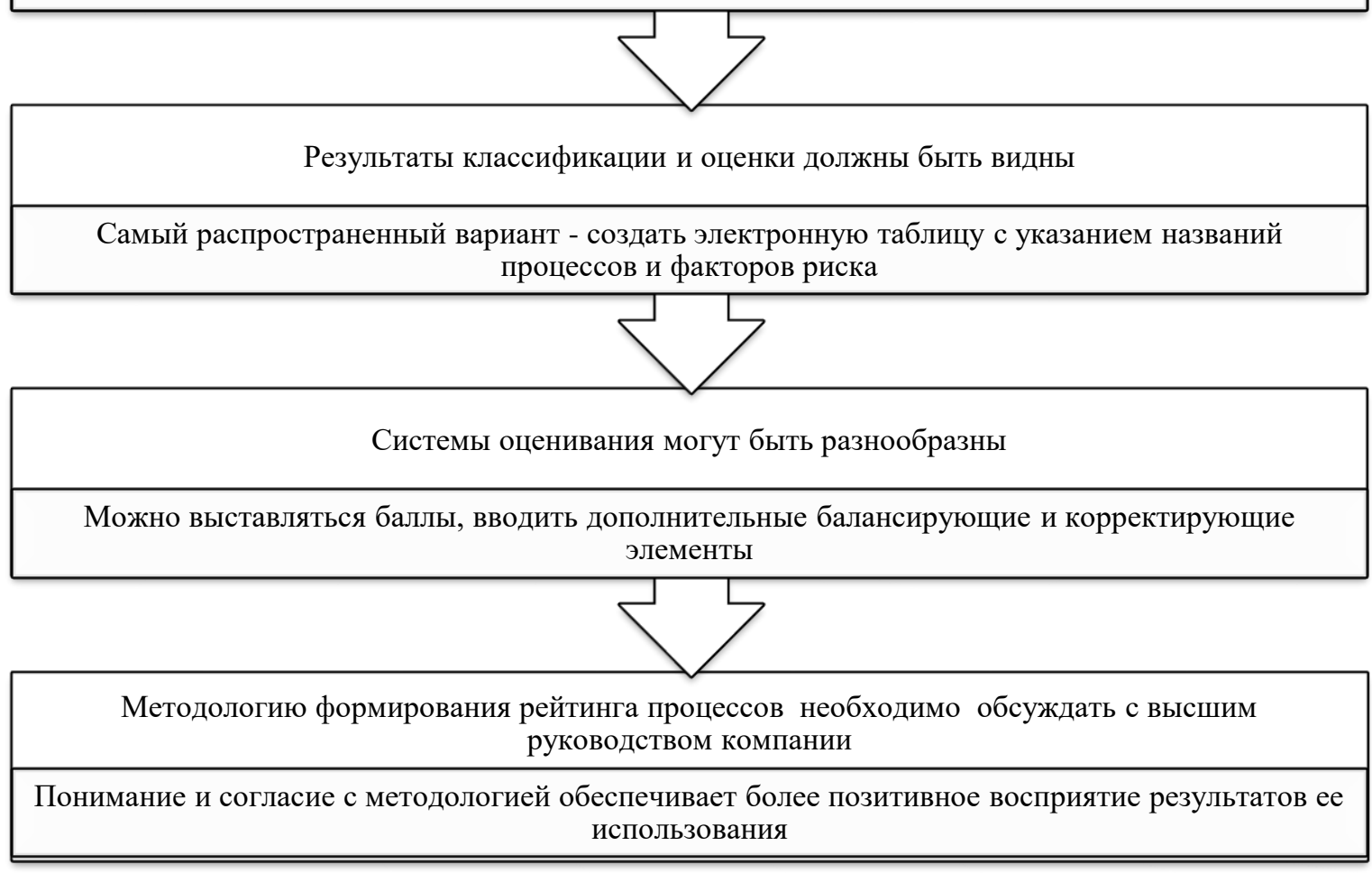

Рисунок 1 - Особенности упрощенного риск-ориентированного подхода в работе службы внутреннего аудита

Представленные на рисунке 1 особенности упрощенного рискориентированного подхода в работе службы внутреннего аудита предполагают следующую последовательность действий:

- формирование списка процессов (подпроцессов, этапов подпроцессов);

- формирование факторов риска.

Оценка влияния выбранных факторов риска на степень достижения цели процессов позволяет сформировать рейтинг рискованности процессов.

При использовании расширенного метода за отправную точку берется список рисков компании, их вероятность, оценивается карта рисков, что создает следующую цепочку действий: создание карты рисков, выбор наиболее важных , преобразование рисков стратегию аудита. 
организации необходима эффективная система управления рисками, основанная на своевременном выявлении, предотвращении или минимизации рисков. Каждый риск требует комплексного подхода.

На рисунке 2 рассмотрены преимущества риск-ориентированного подхода в внутреннему аудиту в современных условиях.

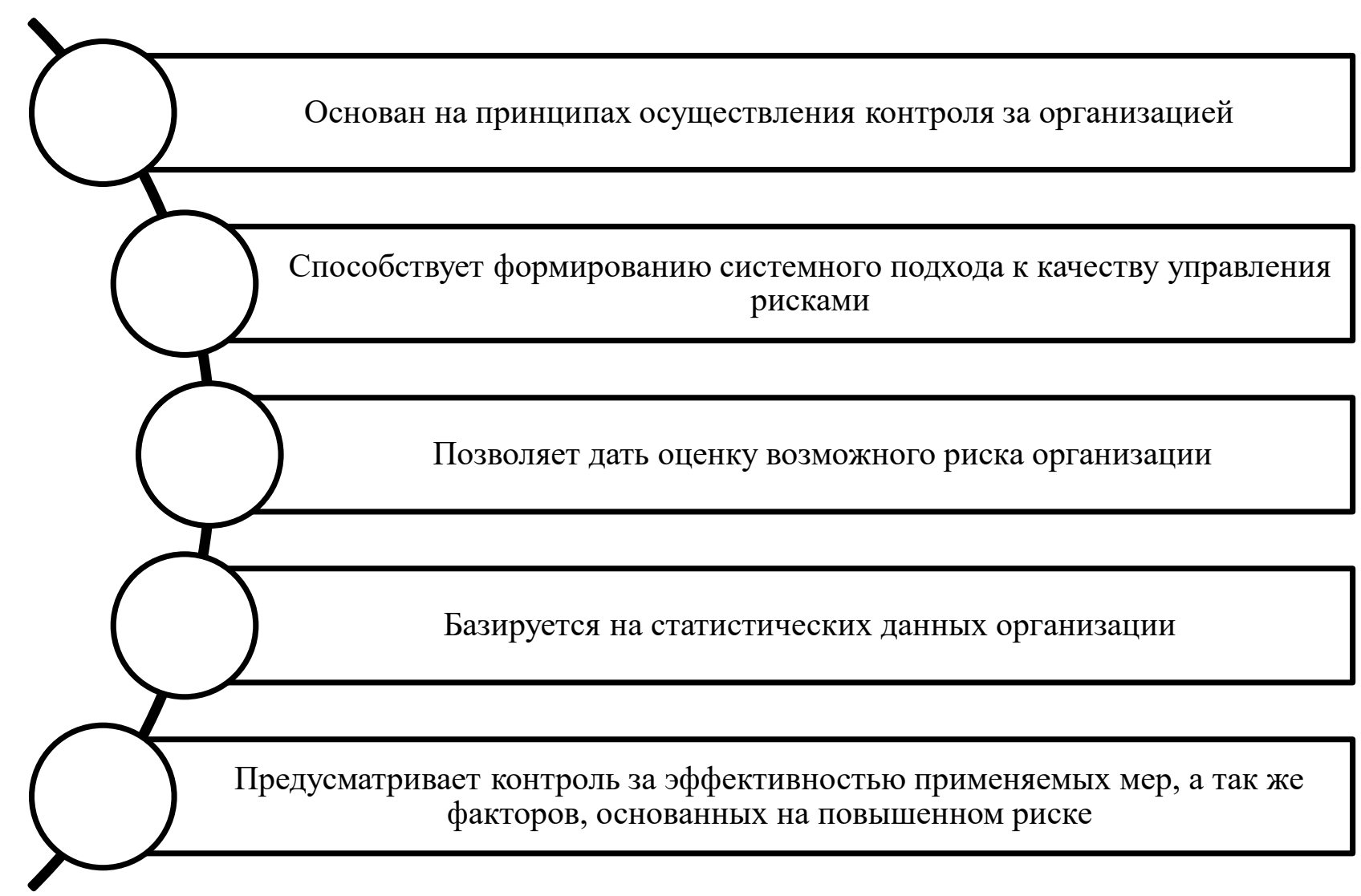

Рисунок 2 - Преимущества риск-ориентированного подхода к внутрееному аудиту

Функция управления рисками является обязанностью руководства. Внутренний аудит отслеживает и оценивает эффективность системы управления рисками. Переход к внутреннему контролю и рискориентированному аудиту необходим. Отлаженная система внутреннего контроля и риск-ориентированного аудита позволяет изучить деятельность организаций, а также разработать необходимые меры по повышению их эффективности с учетом требований нормативных актов и существующей международной и российской практики в сфере внутреннего контроля и аудита. 


\section{Список использованных источников:}

1. Будунова Н.И. Задачи аудита отчетности и пути его развития в России // Учет и контроль. - 2018. - № 4. - С. 2 - 8.

2. Буньковский Д.В. Методы минимизации рисков предприятия // Вопросы управления. - 2018. - № 5 (35). - С. 125-129.

3. Изварина Н.Ю., Мирошников М.М. Современная концепция построения системы корпоративной безопасности // Актуальные проблемы социальногуманитарных наук: сборник научных трудов по материалам Международной научно-практической конференции 30 ноября 2017 г.: в 6 ч. / Под общ. ред. Е. П. Ткачевой. - Белгород: ООО Агентство перспективных научных исследований (АПНИ), 2017. - Часть III. - 154 с. (c. 76-80).

4. Изварина Н.Ю., Алботова А.В. Внутренний аудит в системе корпоративного управления // Молодой ученый. - 2018. - № 19 (205). - С. 46-47.

URL https://moluch.ru/archive/205/50148/ (дата обращения: 16.10.2020).

5. Изварина Н. Ю. Методические аспекты проведения внутреннего аудита в системе экономической безопасности компании // Правовые вопросы обеспечения экономической безопасности государства в условиях автоматизации общества: сборник научных статей Всероссийской научнопрактической конференции 06 апреля 2018 г., г. Ростов-на-Дону / под ред. дра социол. наук, канд. юрид. наук, доц. Исаковой Ю. И. Ростов н/Д, 2018. C. $417-422$.

6. Киркач Ю.Н. Формирование системы внутрикорпоративного контроля в организации // Аудиторские ведомости. - 2017. - №1-2. - С.161 - 166.

7. Патенкова В.Ю. Внутренний контроль в корпорациях // Право и экономика, 2017. - № 8. - C. 33-36.

8. Филевская Н.А. Стратегический внутренний аудит корпоративного управления // Современные подходы к решению финансово-экономических проблем: сбор. науч. труд. Ульяновск: УтГТУ, 2013. - С.90-97. 


\section{Spisok-jispolzovannyh-istochnikov}

1. Budunova N.I. Zadachi audita otchetnosti i puti ego razvitiya $v$ Rossii // Uchet i kontrol. - 2018. - № 4. - S. 2 - 8.

2. Bun'kovskij D.V. Metody minimizacii riskov predpriyatiya // Voprosy upravleniya. - 2018. - № 5 (35). - S. 125-129.

3. Izvarina N.Y., Miroshnikov M.M. Sovremennaya koncepciya postroeniya sistemy korporativnoj bezopasnosti // Aktual'nye problemy social'nogumanitarnyh nauk: sbornik nauchnyh trudov po materialam Mezhdunarodnoj nauchno-prakticheskoj konferencii 30 noyabrya 2017 g.: v 6 ch. / Pod obshch. red. E. P. Tkachevoj. - Belgorod: OOO Agentstvo perspektivnyh nauchnyh issledovanij (APNI), 2017. - CHast' III. - 154 s. (s. 76-80).

4. Izvarina N.Y., Albotova A.V. Vnutrennij audit $\mathrm{v}$ sisteme korporativnogo upravleniya // Molodoj uchenyj. - 2018. - № 19 (205). - S. 46-47. URL https://moluch.ru/archive/205/50148/ (data obrashcheniya: 16.10.2020).

5. Izvarina N. Y. Metodicheskie aspekty provedeniya vnutrennego audita v sisteme ekonomicheskoj bezopasnosti kompanii // Pravovye voprosy obespecheniya ekonomicheskoj bezopasnosti gosudarstva $\mathrm{V}$ usloviyah avtomatizacii obshchestva: sbornik nauchnyh statej Vserossijskoj nauchnoprakticheskoj konferencii 06 aprelya 2018 g., g. Rostov-na-Donu / pod red. d-ra sociol. nauk, kand. yurid. nauk, doc. Isakovoj YU. I. Rostov n/D, 2018. S. 417-422.

6. Kirkach Y.N. Formirovanie sistemy vnutrikorporativnogo kontrolya $\mathrm{v}$ organizacii // Auditorskie vedomosti. - 2017. - №1-2. - S.161 - 166.

7. Patenkova V.Y. Vnutrennij kontrol' $\mathrm{v}$ korporaciyah // Pravo i ekonomika, 2017. - № 8. - S. 33-36.

8. Filevskaya N.A. Strategicheskij vnutrennij audit korporativnogo upravleniya // Sovremennye podhody k resheniyu finansovo-ekonomicheskih problem: sbor. nauch. trud. Ul'yanovsk: UtGTU, 2013. - S.90-97. 